ASIMTOT: JURNAL KEPENDIDIKAN MATEMATIKA

Volume 1 Nomor 1, Januari - Mei 2019, halaman 27 - 32

Tersedia Daring pada https://journal.unwira.ac.id/index.php/Asimtot

\title{
STUDI ETNOMATEMATIKA PADA BUDAYA MASYARAKAT LARANTUKA
}

\section{ETHNOMATHEMATICS STUDY IN LARANTUKA CULTURE}

\author{
Ni Ketut A. Agustini, Samuel I.Leton, Aloysius J. Fernandez \\ Universitas Katolik Widya Mandira \\ artantiguzel@gmail.com, letonsamuel@gmail.com,fndz1586@gmail.com
}

\begin{abstract}
Abstrak: Lingkungan dapat menjadi sebuah sumber belajar dalam proses pembelajaran matematika yang berkaitan dengan dunia nyata. Salah satu sumber belajar pada lingkungan adalah budaya. Pelajaran matematika yang dipelajari peserta didik di sekolah terkadang berbeda dengan masalah matematik yang ditemui dalam kehidupan sehari-hari, menyebabkan sulitnya peserta didik menghubungkan keterkaitan antara konsep matematik yang bersifat formal dengan permasalahan pada budaya. Etnomatematika menghubungkan budaya dengan pembelajaran matematika. Tujuan dari penelitian ini adalah untuk memperoleh gambaran tentang nilai matematik yang tumbuh dan berkembang pada budaya masyarakat Larantuka. Jenis penelitian ini adalah penelitian kualitatif dengan desain etnografi. Pengumpulan data melalui observasi, wawancara dan dokumentasi. Subjek dalam penelitian ini sebanyak tiga orang yang diambil secara purposive terhadap tokoh masyarakat yang mengetahui dan memahami dengan baik tentang rumah adat. Objek dari penelitian ini adalah rumah adat Waibalun. Hasil analisis data menunjukan bahwa adanya a) Aktivitas Etnomatematika dalam proses pembuatan rumah adat Waibalun, yakni aktivitas mengukur, mengitung, dan mendesain. b) Nilai-nilai matematis yang terdapat di rumah adat Waibalun, yakni sudut, persegi panjang, segitiga, trapesium, tabung, dan refleksi.
\end{abstract}

Kata Kunci: Etnomatematika, Budaya, Rumah Adat

Abstract: The environment can become a source of learning in a process of mathematical learning related to the real world. One source learning in the environment is cultural. Mathematical lessons that studied educated participants at school are sometimes different to important transatic problems that encountered in everyday life, makes it more difficult learning participants linking the links of furatic concepts that are formal with issues of culture. Etnomathematics connects cultures with mathematics learning. The purpose of this research is to obtain the description of the value of the impostor's value and growing up to the cultural society of Waibalun. This type of research is a qualitative research with the Etnographic design. Data collection by observation, interviews and documentation. The subject in this study is three person taken Purposive against public figures who learn and understand well about indigenous homes. The object of this research is the Waibalun indigenous home. The results of data analysis show that a) Etnomathematical activity in the process of making Waibalun indigenous homes, that is measuring, counting and designing; $b) \quad T h e$ mathematical values were found in the Waibalun indigenous home consist of, the angle, rectangle, triangle, trapezium, tube and reflections

Keywords: Etnomathematics, Culture, Indigenous Home

Cara Sitasi: Ni Ketut,A.A., Samuel,I.L., \& Aloysius, J.F. (2019). Studi Etnomatematika Pada Budaya Masyarakat Larantuka. Asimtot; Jurnal Kependidikan Matematika, 1(1), 27 - 32 
Istilah Etnomatematika pertama kali dikemukakan oleh seorang matematikawan Brasil pada tahun 1977, bernama D'Ambrosio. definisi etnomatematika menurut D'Ambrosio adalah: The prefik ethno is today acceptep as a very broad term that refers to the social. Cultural contex and therefere includes languange, jargon, and codes of behavior, myths and symbols. The derivation of mathema is difficult, but tends to mean to explain, to know, to understand, and to do activities such as ciphering, measuring, classifying, inferring, and modeling. The suffix ticsis derived from techneand has the same root as technigue (Orey, 2011).

Secara harafiah, awalan ethno mengacu pada kelompok kebudayaan yang dapat dikenali, seperti perkumpulan suku di suatu negara dan kelas-kelas profesi di masyarakat, termasuk pula bahasa dan kebiasaan mereka sehari-hari. Kemudian mathema berarti menjelaskan, mengerti, dan mengelola hal-hal nyata secara spesifik dengan menghitung, mengukur, mengklarifikasi, mengurutkan, dan memodelkan suatu pola yang muncul pada suatu lingkugan. Akhiran tics mengandung arti seni dalam teknik. Dengan demikian etnomatematika adalah suatu ilmu yang digunakan untuk memahami bagaimana matematika diadaptasi dari sebuah budaya.

Dalam proses pembelajaran matematika peserta didik berpendapat bahwa matematika merupakan mata pelajaran yang sulit (Hastoro, 2012). Hal ini dikarenakan proses pembelajarannya yang cenderung terlalu teoritis, kurang kontekstual, dan bersifat semu. Pelajaran matematika yang diajarkan di sekolah terkadang ditemukan berbeda dengan permasalahan matematika yang ditemukan dalam kehidupan sehari-hari. Ketidaksesuaian permasalahan matematika yang ditemukan di sekolah dengan yang di kehidupan sehari-hari menyebabkan sulitnya peserta didik menghubungkan konsep-konsep matematika yang bersifat formal dengan permasalahan dalam dunia nyata.

Penelitian ini mengeksplorasi nilai matematik yang tumbuh dan berkembang pada budaya masyarakat Larantuka. Dengan mengetahui nilai matematik yang tumbuh dan berkembang dalam masyarakat Larantuka akan menambah sumber belajar bagi peserta didik.

\section{Metode Penelitian}

Penelitian ini digolongkan dalam jenis penelitian kualitatif dengan desain Etnografi. Penelitian menggunakan desain Etnografi dengan tujuan untuk menggambarkan bagaimana masyarakat mengorganisasikan budaya dalam pikiran masyarakat setempat dan kemudian menggunakan budaya tersebut dalam kehidupan. Subjek dalam penelitian ini sebanyak tiga orang yang diambil secara purposive. Objek dalam penelitian ini adalah rumah adat masyarakat Waibalun. Dalam pengumpulan data, peneliti menggunakan observasi, dokumentasi dan wawancara.

Teknik analisis data yang digunakan adalah analisis domain, analisis taksonomi dan analisis komponensial. Analisis domain dimana peneliti menemukan domain yakni aktivitas Etnomatematika yang ditemukan ketika melakukan observasi yang dibantu dengan dokumentasi berupa foto. Selanjutnya peneliti melakukan analisi taksonomi untuk menggali informasi lebih mendalam lagi mengenai domain yang ditemukan sebelumnya. Setetah itu peneliti melakukan 
analisis komponensial yakni peneliti lebih memfokuskan nilai-nilai matematis yang terdapat dalam budaya (rumah adat) masyarakat Larantuka. Setelah analisis peneliti mengaitkan nilai matematis yang ditemukan dengan materi di sekolah untuk dijadikan sumber belajar siswa.

\section{Hasil Penelitian dan Pembahasan}

\section{Hasil}

\section{Aktivitas Matematis Dalam Pembuatan Rumah Adat Korke Waibalun}

Peneliti menemukan adanya aktivitas matematis dalam proses pembuatan rumah adat ini, yakni:

\section{Aktivitas Mengukur}

Aktivitas mengukur ini dilakukan oleh masyarakat dalam mempersiapkan/mencari bahan-bahan bangunan. Sebelum adanya alat ukur baku seperti saat ini, masyarakat setempat menggunakan bagian tubuh yakni 'Depa' sebagai alat ukur. Satu depa sama dengan jarak antara ujung tangan kiri sampai ke ujung tangan kanan, dengan posisi kedua tangan direntangkan (ukuran tangan orang dewasa).

\section{Aktivitas Menghitung}

Aktivitas menghitung ini dilakukan masyarakat pada saat mempersiapkan bahanbahan bangunan yang dibutuhkan. Semua bahan bangunan sudah diperhitungkan, jika bentuk bangunan seperti ini, maka banyaknya rumput yang digunakan, banyaknya tiang yang harus dibutuhkan dan banyaknya kayu yang digunakan untuk membuat kuda-kuda atap. Mengenai ketentuan berapa banyak bahan yang dibutuhkan untuk membangun rumah adat, sudah diperhitungkan oleh orang yang ahli (tukang) dalam membangun rumah adat, yang dulu dikenal dengan istilah 'Laba Belewet'.

\section{Aktivitas Mendesain/Merancang}

Sebelum dibuatkan rumah adat Waibalun, telah diadakan musyawarah mufakat bersama masyarakat untuk membuat rumah adat. Orang yang mendesain/merancang bangunan rumah adat ini adalah laba belewet (tukang).

\section{Nilai Matematis Pada Rumah Adat Waibalun}

Sudut

Sudut dibentuk oleh dua sinar garis yang bersekutu titik pangkalnya, titik pangkal itu disebut sudut (Astuti, 2010). Sudut yang terdapat di pondasi rumah adat Waibalun adalah sudut siku-siku. Sudut yang terdapat di atap adalah sudut lancip dan sudut tumpul. Berikut gambar tentang sudut yang terdapat di rumah adat :

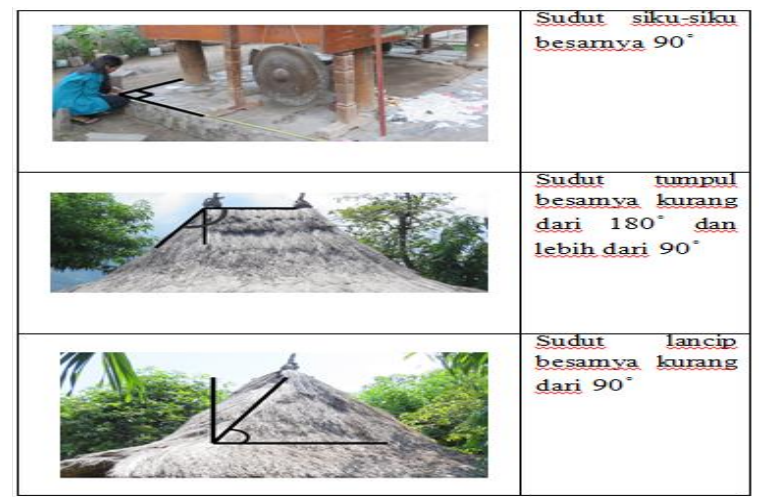

Gambar 1. Sudut Pada Rumah adat

Persegi Panjang

Bentuk dari pondasi Rumah Adat Korke Waibalun ini memiliki ukuran dan bentuk sebagai berikut : 


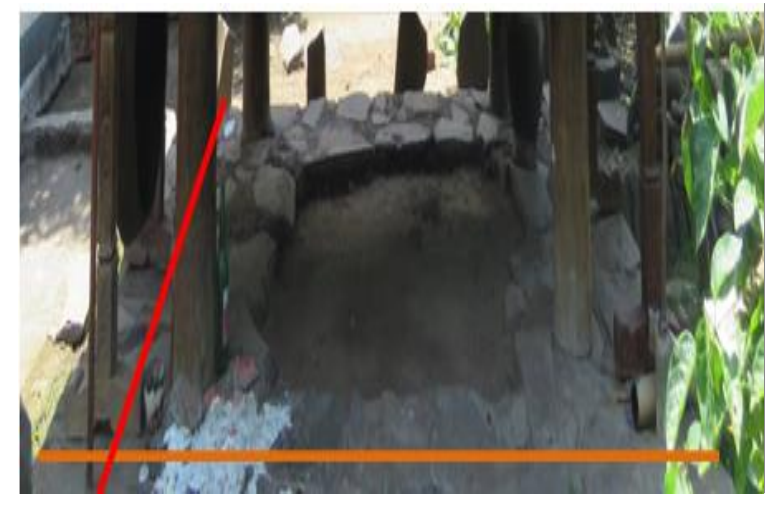

Gambar 2.Pondasi Rumah Adat Waibalun

Gambar 2. merupakan pondasi rumah adat Waibalun yang dibuat dari batu ceper (batu mera). Ukuran panjang dan lebar dari pondasi rumah adat ini adalah $370 \mathrm{~cm}$ dan $320 \mathrm{~cm}$.

Segitiga

Bentuk segitiga ditemukan pada atap bagian samping Rumah Adat Waibalun. Berikut bentuk serta ukuran dari atap bagian samping dari rumah adat:

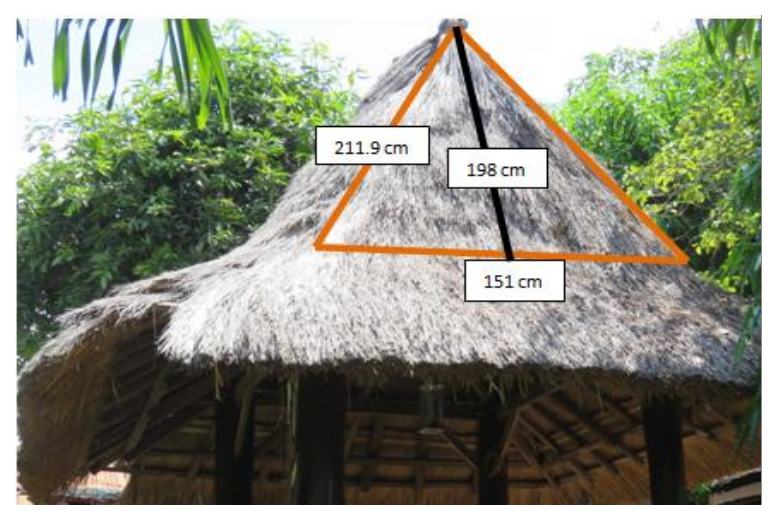

Gambar 3. Atap Sampin Rumah Adat Waibalun

Gambar 3. merupakan atap samping rumah adat Waibalun yang terbuat dari batang pohon lontar untuk rangkanya, dan rumput ilalang untuk menutupi rangkanya. Atap berbentuk segitiga ini memiliki panjang alas $151 \mathrm{~cm}$, tinggi $198 \mathrm{~cm}$ dan sisi miringnya $211,9 \mathrm{~cm}$.

\section{Trapesium}

Terdapat beberapa bentuk trapesium pada rumah adat Waibalun yang salah satunya ditemukan pada atap bagian depan dan belakang ( bentuk dan ukuran yang sama). Berikut bentuk serta ukuran dari atap bagian depan dari rumah adat:

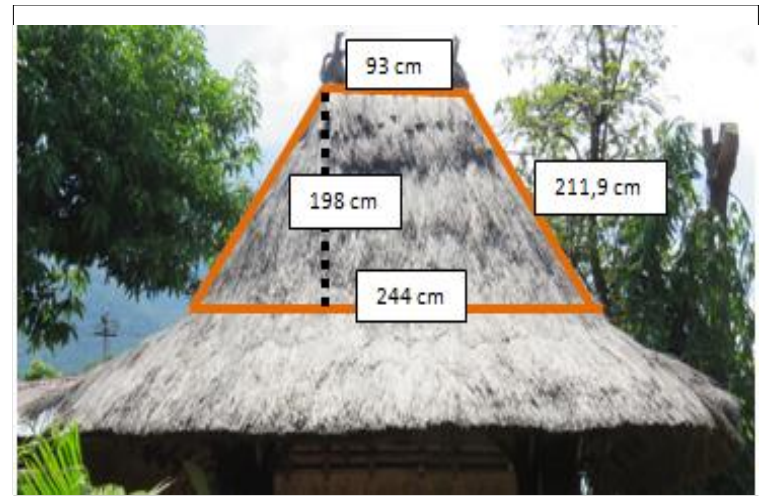

Gambar 4.Atap Bagian Depan Rumah Adat Waibalun

Gambar di atas merupakan atap bagian depan rumah adat Waibalun yang terbuat dari batang pohon lontar untuk rangkanya, dan rumput ilalang untuk menutupi rangkanya. Atap berbentuk trapesium ini memiliki panjang alas $244 \mathrm{~cm}$, tinggi $198 \mathrm{~cm}$, sisi miringnya $211,9 \mathrm{~cm}$ dan atapnya $93 \mathrm{~cm}$.

\section{Tabung}

Tabung merupakan bagian dari geometri bangun ruang. Bentuk tabung ditemukan pada tiang Rumah Adat Korke Waibalun. Berikut bentuk serta ukuran dari tiang Rumah Adat Korke Waibalun : 


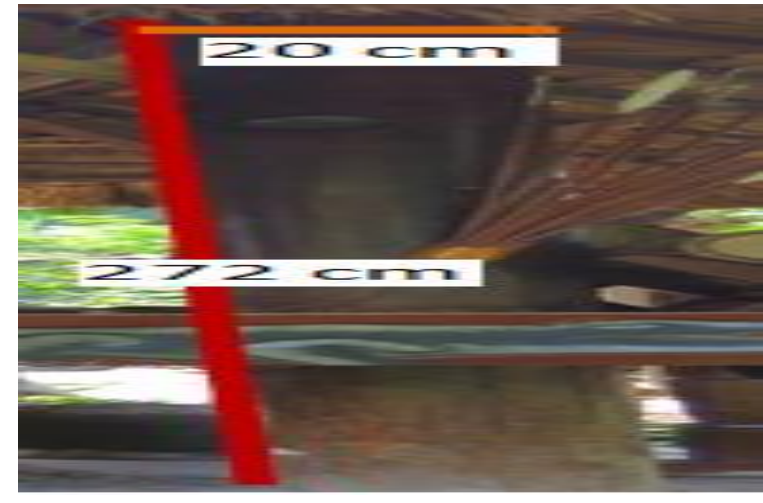

Gambar 5. Tiang Rumah Adat Waibalun

Gambar di atas merupakan tiang dari Rumah Adat Waibalun yang dibuat dari batang pohon lontar. Tiang ini memiliki tinggi $272 \mathrm{~cm}$ dan berdiameter $20 \mathrm{~cm}$.

\section{Pembahasan}

Berdasarkan hasil penelitian yang ada, peneliti menemukan keterkaitan nilai matematis yang ada di rumah adat Waibalun dengan materi matematika pada jenjang SMP antara lain :

Tabel 1. Sumber Belajar

\begin{tabular}{|c|c|c|c|}
\hline No & $\begin{array}{l}\text { Nilai } \\
\text { Matemati } \\
\text { s }\end{array}$ & $\begin{array}{l}\text { Materi } \\
\text { Pembelajara } \\
\text { n }\end{array}$ & $\begin{array}{l}\text { Manfaat Bagi } \\
\text { Siswa }\end{array}$ \\
\hline 1. & Sudut & $\begin{array}{lr}\text { Materi } & \text { Garis } \\
\text { dan Sudut } \\
\text { terdapat di } \\
\text { kelas VII }\end{array}$ & $\begin{array}{lr}\text { Siswa } & \text { dapat } \\
\text { mencermati } \\
\text { masalah } & \text { sehari- } \\
\text { hari } & \text { secara } \\
\text { alamiah } & \text { yang } \\
\text { berkaitan } & \text { dengan } \\
\text { sudut } & \end{array}$ \\
\hline 2. & $\begin{array}{l}\text { Persegi } \\
\text { panjang, } \\
\text { segitiga, } \\
\text { trapesium, }\end{array}$ & $\begin{array}{l}\text { Materi } \\
\text { Segiempat } \\
\text { dan Segitiga } \\
\text { terdapat di } \\
\text { kelas VII }\end{array}$ & $\begin{array}{l}\text { Siswa dapat } \\
\text { mengidentifikasika } \\
\text { n dan menjelaskan } \\
\text { benda-benda yang } \\
\text { alamiah berbentuk } \\
\text { persegi panjang, } \\
\text { segitiga, dan } \\
\text { trapesium. }\end{array}$ \\
\hline 3. & Tabung & $\begin{array}{l}\text { Materi } \\
\text { Bangun } \\
\text { Ruang Sisi }\end{array}$ & $\begin{array}{l}\text { Siswa dapat } \\
\text { mengidentifikasika } \\
\mathrm{n} \text { dan menjelaskan }\end{array}$ \\
\hline
\end{tabular}

\begin{tabular}{clrlr} 
& Lengkung & & \multicolumn{2}{l}{ benda-benda yang } \\
terdapat di & alamiah berbentuk \\
4. Refleksi & kelas IX & tabung. \\
& Materi & Siswa dapat \\
& Transformasi & menentukan unsur- \\
terdapat di & unsur yang \\
& kelas IX & berkaitan dengan \\
& & sifat-sifat \\
& & transformasi pada \\
& & materi refleksi \\
\hline
\end{tabular}

\section{Simpulan dan Saran}

\section{Simpulan}

Setelah mempelajari, mencermati, dan menggali informasi terhadap Rumah Adat Korke Waibalun, maka dapat diperoleh halhal sebagai berikut:

\section{Aktivitas Etnomatematika}

Terdapat aktivitas etnomatematika dalam masyarakat Waibalun saat proses pembuatan rumah adat. Aktivitas yang terdapat di masyarakat yaitu aktivitas mengukur, mengitung dan mendesain/merancang.

Nilai Matematis yang Terdapat di Rumah Adat Korke Waibalun

Nilai matematis yang ditemukan pada rumah adat Korke Waibalun berkaitan dengan geometri yakni

\section{Sudut}

Terdapat beberapa sudut di Rumah Adat Waibalun ini yaitu sudut siku-siku yang ada di pondasi rumah dan sudut lancip dan tumpul yang ada di atap rumah. Materi mengenai sudut dipelajari di kelas VII pada materi garis dan sudut. 
Persegi panjang dapat dilihat dari bentuk pondasi Rumah Adat Waibalun. Segitiga dan trapesium terdapat di bentuk dari atap Rumah Adat Waibalun. Persegi panjang, segitiga dan trapesium ada pada materi segiempat dan segitiga di kelas VII.

\section{Tabung}

Tabung dapat dilihat dari bentuk tiang Rumah Adat Waibalun. Tabung ada pada materi bangun rumag sisi lengkung di kelas IX.

Refleksi

Refleksi/pencerminan dapat dilihat dari gambar dua ekor buaya yang ada pada Rumah Adat Waibalun. Refleksi/pencerminan ada pada materi Transformasi di kelas IX.

\section{Saran}

Pengumpulan data dan menemukan nilai matematis pada Rumah Adat Waibalun dilakukan sendiri oleh peneliti namun peneliti belum menerapkan langsung di sekolah. Kiranya ada tindak lanjut dari penelitian ini untuk menerapkannya di sekolah.

Penelitian ini hanya untuk menemukan nilai matematis yang terdapat di Rumah Adat Waibalun dan sebagai sumber belajar secara umum yang tidak memperhatikan jenjang tingkatan sekolah.

Untuk meningkatkan pembelajaran yang saat ini lebih menekankan pada aspek kebudayaan, ada baiknya dibuatkan modul yang dikaitkan dengan Etnomatematika.
Astuti, A.Y. dan Miyanto. (2010). Detik-Detik Ujian Nasional Matematika SMP/MTs. Klaten: Intan Pariwara.

Hardiarti, S. (2017). Etnomatematika: Aplikasi Bangun Datar Segi Empat Pada Candi Muaro Jambi. Aksioma, Vol. 8, No. 2 , 99-110.

Hastoro, W. (2012). Menentukan Luas Daerah Bangun Datar Dengan Papan Berpetak Untuk siswa SMP Kelas VII. Prosiding, 924-936.

Indriaini Popi. (2016). Implementasi Etnomatematika Berbasis Budaya Lokal Dalam Pembelajaran Matematika Pada Jenjang Sekolah Dasar(Skripsi). Falkutas Tarbiyah Dan Keguruan. Lampung: Institut Agama Islam Negeri (IAIN).

Orey, \& M. R. (2011). Ethnomathematics : the cultural aspects of mathematics. Revista Latinoamericana de Etnomatematica , 35.

Pramono, A. (2013). Media Pendukung Pembelajaran Rumah Adat Indonesia Menggunakan Augmented Reality. Jurnal ELTEK, Vol 11 Nomor 01 , 122-130.

Republik Indonesia. Undang-Undang dasar 1945

Subchan, d. (2018). Buku Guru Matematika SMP/MTs Kelas IX. Jakarta: Kemendikbud.

Turmudi. (2018). Kajian Etnomatematika: Belajar Matematika Dengan Melibatkan Unsur Budaya. Prosiding Seminar Nasional Pendidikan Matematika Etnomatnesia , 40.

Widiastuti. (2013). Analisis Swot Keragaman Budaya Indonesia. Jurnal Ilmiah Widya , 8-14. 